\title{
Characterization of a second cell-associated Arg-specific cysteine proteinase of Porphyromonas gingivalis and identification of an adhesin-binding motif involved in association of the prtR and prtK proteinases and adhesins into large complexes
}

\author{
Nada Slakeski, Peter S. Bhogal, Neil M. O’Brien-Simpson \\ and Eric C. Reynolds
}

Author for correspondence: Eric C. Reynolds. Tel: +6139341 0270. Fax: +61393410236. e-mail: e.reynolds@dent.unimelb.edu.au

Biochemistry and Molecular Biology Unit, School of Dental Science, The University of Melbourne, 711 Elizabeth Street, Melbourne, Victoria, Australia 3000
Porphyromonas gingivalis has been associated with the development of adult periodontitis and cysteine proteinases with Arg- and Lys-specific activity have been implicated as major virulence factors. In a cell sonicate of $P$. gingivalis W50, a complex of non-covalently associated proteins has been previously characterized. This complex is composed of a $45 \mathrm{kDa}$ Arg-specific, calciumstabilized cysteine proteinase (PrtR45), a 48 kDa Lys-specific cysteine proteinase (PrtK48) and seven sequence-related adhesins designated PrtR44, PrtR15, PrtR17, PrtR27, PrtK39, PrtK15 and PrtK44, with all proteins being encoded by the two genes prtR and prtK. It has been proposed that these noncovalently associated complexes form extracellularly after autolytic processing of the PrtR and PrtK polyproteins, with the adhesins binding to the proteinases (PrtR45 and PrtK48) and autoaggregating. Another form of the cell-associated, Arg-specific, calcium-stabilized cysteine proteinase is described here.

Designated PrtRII50, it is a discrete 50 kDa protein with no adhesin-association and has enzymic characteristics and an inhibitor/activator profile almost identical to PrtR45. The PrtRII50 proteinase is encoded as a preproprotein by a second gene, prtRII, with high sequence similarity to PrtR except that it lacks the C-terminal adhesin domains. A comparison of the deduced amino acid sequence of PrtRII50 with that of the adhesin-associated proteinases PrtR45 and PrtK48 revealed that PrtRII50 does not contain a C-terminal motif that is conserved in PrtR45 and PrtK48. Related motifs are also found in the adhesin domains of PrtR and PrtK. It is proposed that this conserved motif is an adhesin-binding motif (ABM) involved in association of the PrtR and PrtK proteinases and adhesins into large complexes, as the PrtR-PrtK proteinase-adhesin complex inactivated by $\boldsymbol{N}-\alpha-p$-tosyl-L-lysine chloromethyl ketone (TLCK) was shown to bind specifically to a synthetic peptide corresponding to the conserved motif in a competitive binding assay.

Keywords: Porphyromonas gingivalis, second Arg-specific cysteine proteinase, adhesinbinding motif

Abbreviations: ABM, adhesin-binding motif; Bz-L-Arg-pNA, benzoyl-L-Arg-p-nitroanilide; DBU, 1,8-diazabicyclo[5.4.0]undec-7-ene; DIPEA, diisopropylethylamine; DMF, $N, N$-dimethylformamide; EDT, ethanedithiol; HBTU, O-benzotriazole- $N, N, N^{\prime}, N^{\prime}$-tetramethyluronium hexafluorophosphate; HOBt, 1-hydroxybenzotriazole; TFA, trifluoroacetic acid; Fmoc, 9-fluorenylmethoxycarbonyl; TIPS, triisopropylsilane; TLCK, $N$ - $\alpha$-p-tosyl-L-lysine chloromethyl ketone; z-L-Lys-pNA, benzyloxycarbonyl-L-Lys-p-nitroanilide.

The GenBank accession number for the sequence reported in this paper is AF007124. 


\section{INTRODUCTION}

Porphyromonas gingivalis has been implicated as a major aetiological agent in the development of adult periodontitis, a destructive inflammatory disease of the tooth-supporting tissues (Slots et al., 1986; Maiden et al., 1990; Socransky \& Haffajee, 1992). This bacterium elaborates several putative virulence factors which are proposed to be involved in disease initiation and progression (Cutler et al., 1995). Of these virulence factors, extracellular Arg- and Lys-specific proteinases have been suggested to play a major role in disease pathogenesis (Smalley et al., 1989; Nakayama et al., 1995; Kesavalu et al., 1996) by dysregulation of the host defence and inflammatory responses (Kadowaki et al., 1994; Imamura et al., 1995a, b; Jagels et al., 1996) and by direct proteolytic degradation of host connective tissue and plasma proteins (Ciborowski et al., 1994; Pike et al., 1996).

We have recently characterized the cell-associated Argand Lys-specific proteinases of $P$. gingivalis W50 as noncovalently associated complexes of a $45 \mathrm{kDa}$ Argspecific, calcium-stabilized cysteine proteinase, a $48 \mathrm{kDa}$ Lys-specific cysteine proteinase and several sequencerelated adhesins (Bhogal et al., 1997). The $45 \mathrm{kDa}$ Argspecific cysteine proteinase, designated PrtR45, appeared similar to enzymes characterized in $P$. gingivalis culture supernatants (Chen et al., 1992; Curtis et al., 1996). We then further identified two genes, $p r t R$ and $p r t K$, that encoded all the proteins of these proteinase-adhesin complexes (Slakeski et al., 1996; Bhogal et al., 1997). The prtR gene encodes a polyprotein with a preprofragment followed by the $45 \mathrm{kDa}$ Arg-specific proteinase (PrtR45) and four sequence-related adhesin domains PrtR44, PrtR15, PrtR17 and PrtR27 in that order (Slakeski et al., 1996). The prtK gene is very similar in that it also encodes a polyprotein with a preprofragment followed by the $48 \mathrm{kDa}$ Lys-specific proteinase (PrtK48) and three C-terminal adhesin domains, PrtK39, PrtK15 and PrtK44, all being sequencerelated and similar to the PrtR adhesins (Bhogal et al., 1997). All domains of the PrtR and PrtK polyproteins are preceded by Arg or Lys residues - consistent with autolytic processing. It is proposed that the PrtR and PrtK proteins are secreted as mature 160 and $163 \mathrm{kDa}$ proteins, respectively, after processing to remove their preprofragments. The mature PrtR and PrtK proteins associate or remain unassociated and are then autolytically processed to release the PrtR45 and PrtK48 proteinase domains as well as the seven sequence-related adhesins. The adhesins, by containing multiple repeat sequences, possess multiple binding sites that are capable of binding not only to host proteins and cells but also to the Arg-and Lys-specific proteinases and themselves to produce large non-covalently associated aggregates (Bhogal et al., 1997).

During the analysis of the $p r t R$ and $p r t K$ genes we noted that a Southern blot of $P$. gingivalis W50 genomic DNA contained two BamHI and two HindIII restriction fragments which hybridized with an oligonucleotide probe designed using the $\mathrm{N}$-terminal sequence of the PrtR45 Arg-specific proteinase (Slakeski et al., 1996). This result suggested the presence of a second closely related gene encoding another Arg-specific proteinase. Here we describe the purification and characterization of the second Arg-specific proteinase of $P$. gingivalis and the cloning and sequence analysis of its gene, prtRII.

\section{METHODS}

Materials. O-Benzotriazole- $N, N, N^{\prime}, N^{\prime}$-tetramethyluronium hexafluorophosphate (HBTU), 1-hydroxybenzotriazole (HO$\mathrm{Bt}$ ), diisopropylethylamine (DIPEA), N,N-dimethylformamide (DMF), piperidine, trifluoroacetic acid (TFA) and 9fluorenylmethoxycarbonyl (Fmoc)-protected amino acids were obtained from Auspep (Melbourne, Australia). Triisopropylsilane (TIPS) and ethanedithiol (EDT) were obtained from Aldrich. 1,8-Diazabicyclo[5.4.0]undec-7-ene (DBU) was obtained from Sigma. Phenol and diethyl ether were obtained from $\mathrm{BDH}$. Unless otherwise stated chemicals were of peptide synthesis grade or its equivalent.

Bacterial strain and growth conditions. Lyophilized cultures of $P$. gingivalis W50 were kindly provided by Professor P. Marsh (PHLS, Centre for Applied Microbiology and Research, Wiltshire, UK). P. gingivalis W50 was grown anaerobically (Bhogal et al., 1997) and Escherichia coli JM109 and LE392 strains were grown as previously described (Slakeski et al., 1996).

Purification of the $\mathbf{5 0} \mathrm{kDa}$ Arg-specific proteinase. P. gingivalis W50 was grown in batch culture (5l) and harvested at late-exponential phase by centrifugation $(5000 \mathrm{~g}, 20 \mathrm{~min}$, $\left.4^{\circ} \mathrm{C}\right)$. Cells were washed once with $150 \mathrm{ml}$ TC buffer $(20 \mathrm{mM}$ Tris/ $/ \mathrm{HCl}, \mathrm{pH} 7 \cdot 4$, and $5 \mathrm{mM} \mathrm{CaCl}_{2}$ ) containing $50 \mathrm{mM} \mathrm{NaCl}$ and sonicated as described previously (Bhogal et al., 1997). The sonicate was centrifuged $\left(100000 \mathrm{~g}, 30 \mathrm{~min}, 4^{\circ} \mathrm{C}\right)$ and the supernatant filtered $(0.22 \mu \mathrm{m})$ prior to anion-exchange FPLC. The sonicate was applied to an anion-exchange column (Hiload XK 16/10 Q-Sepharose, Pharmacia-LKB) cooled to $4{ }^{\circ} \mathrm{C}$, in multiple injections using a $50 \mathrm{ml}$ superloop (Pharmacia-LKB). The sonicate was eluted using a linear gradient from 0 to $100 \%$ buffer $\mathrm{B}$ over $90 \mathrm{~min}$ at a flow rate of $2.0 \mathrm{ml} \mathrm{min}{ }^{-1} . A_{280}$ was monitored and eluate collected at $4{ }^{\circ} \mathrm{C}$ in $6 \mathrm{ml}$ fractions using a Frac 100 fraction collector (Pharmacia-LKB). Buffer A was TC buffer containing $50 \mathrm{mM} \mathrm{NaCl}$ and buffer B was TC buffer containing $500 \mathrm{mM} \mathrm{NaCl}$. Fractions were analysed for proteolytic and amidolytic activity using azocasein (A-2765, Sigma), benzoyl-L-Arg- $p$-nitroanilide (Bz-L-Arg- $p$ NA, Sigma) and benzyloxycarbonyl-L-Lys$p$-nitroanilide (z-L-Lys- $p$ NA, Calbiochem) as described previously (Bhogal et al., 1997) except that fractions were preincubated with $10 \mathrm{mM}$ cysteine for $10 \mathrm{~min}$ at $25^{\circ} \mathrm{C}$ before the addition of substrate. For the amidolytic assays $A_{410}$ was monitored at as previously described (Bhogal et al., 1997) and the amidolytic activity expressed as $U$, where $1 \mathrm{U}=1 \mu \mathrm{mol}$ substrate converted $\mathrm{min}^{-1}$ at $25^{\circ} \mathrm{C}$. Anion-exchange fractions eluting between 160 and $246 \mathrm{mM} \mathrm{NaCl}$ containing the highest ratio of Arg-specific to Lys-specific activity were washed and concentrated in TC buffer containing $150 \mathrm{mM} \mathrm{NaCl}$ using a Centripep and Centricon-10 concentrators (Amicon) and applied to a gel-filtration column (Superose 12, HR 10/30, Pharmacia-LKB) using TC buffer containing $150 \mathrm{mM} \mathrm{NaCl}$ at a flow rate of $0.3 \mathrm{ml} \mathrm{min}{ }^{-1} . A_{280}$ was monitored and fractions collected at $4{ }^{\circ} \mathrm{C}$ using a Frac 100 fraction collector. The molecular mass values of eluant peaks were determined using gel-filtration molecular mass standards (Pharmacia-LKB). The 
peak eluting at $50 \mathrm{kDa}$ containing only Arg-specific amidolytic activity was washed in TC buffer containing $50 \mathrm{mM} \mathrm{NaCl}$ using a Centricon-10 concentrator (Amicon) and applied to a Mono Q (HR 5/5) anion-exchange column using a $5 \mathrm{ml}$ loop and eluted using a linear gradient of $0-100 \%$ buffer $B$ at a flow rate of $1.0 \mathrm{ml} \mathrm{min}{ }^{-1}$. Buffer $\mathrm{A}$ was $\mathrm{TC}$ buffer containing $150 \mathrm{mM} \mathrm{NaCl}$, buffer B was TC buffer containing $500 \mathrm{mM}$ $\mathrm{NaCl} . A_{280}$ was monitored and fractions collected at $4{ }^{\circ} \mathrm{C}$ using a Frac 100 fraction collector.

SDSPAGE, protein transblot and $\mathrm{N}$-terminal sequence analysis. SDS-PAGE was performed using a Mini Protean II electrophoresis system (Bio-Rad) with $12 \%$ (w/v), $1 \mathrm{~mm}$ separating gels, overlaid with $5 \%$ stacking gels (Laemmli, 1970) and proteins transblotted and N-terminally sequenced as previously described (Bhogal et al., 1997).

Cloning and nucleotide sequence analysis. The $P$. gingivalis W50 LambdaGEM-12 genomic library, described previously (Slakeski et al., 1996), was screened using synthetic oligonucleotides derived from the nucleotide sequence of prtR (Slakeski et al., 1996) corresponding to the N-terminal sequence of $\operatorname{PrtR} 45$. Oligonucleotide probes were $5^{\prime}$ endlabelled using $\left[\gamma_{-}{ }^{32} \mathrm{P}\right] \mathrm{ATP}$ and T4 polynucleotide kinase. Approximately $1.5 \times 10^{4}$ phage were screened by lifting onto Nylon membrane filters and hybridizing with radiolabelled oligonucleotides overnight in hybridization buffer: $6 \times \mathrm{SSC}$ (SSC is $15 \mathrm{mM}$ sodium citrate, $150 \mathrm{mM} \mathrm{NaCl}, \mathrm{pH} 8 \cdot 0$ ), $0 \cdot 25 \%$ SDS, $5 \times$ Denhardt's solution (Sambrook et al., 1989) and $100 \mu \mathrm{g}$ salmon sperm DNA ml ${ }^{-1}$ at $49^{\circ} \mathrm{C}$. Filters were washed extensively in a solution of $2 \times$ SSC containing $0.1 \%$ SDS $(\mathrm{w} / \mathrm{v})$ at $49^{\circ} \mathrm{C}$. Phage from positively hybridizing plaques were purified using standard procedures (Sambrook et al., 1989). Phage DNA was digested with Eco72I and the resulting fragments ligated into SmaI-BAP pUC18 (Pharmacia), which was used to transform E. coli JM109 using the heat-shock procedure (Sambrook et al., 1989). Double-stranded template DNA was sequenced as described previously (Slakeski et al., 1996).

PCR was used to amplify a 991 bp fragment containing the internal Eco72I site encoded by prtRII using the two oligonucleotide primers 5'-CGGCTTCCGTAAAGTC-3' (forward primer identical to bases $657-672$ of $\operatorname{Pr} R I I$ sequence) and $5^{\prime}$ TGGCTACGATGACGATCATACGAC-3' (reverse primer with $96 \%$ identity to bases $1624-1647$ of $p r t R I I)$. The PCR was carried out in a final volume of $100 \mu \mathrm{l}$ and each reaction mixture contained $100 \mathrm{ng} P$. gingivalis W50 genomic DNA, $0.2 \mathrm{mM}$ dNTPs, $1.5 \mathrm{mM} \mathrm{MgCl}_{2}, 100$ pmol of each primer, $20 \mathrm{mM}$ Tris/HCl, pH 8.4, $50 \mathrm{mM} \mathrm{KCl}$ and $2.5 \mathrm{U}$ Taq DNA Polymerase (Gibco-BRL). The reaction mixture was heated at $95^{\circ} \mathrm{C}$ for $3 \mathrm{~min}$ and then subjected to 25 cycles of DNA denaturation at $95^{\circ} \mathrm{C}$ for $30 \mathrm{~s}$, primer annealing at $40^{\circ} \mathrm{C}$ for $1 \mathrm{~min}$ and extension at $72^{\circ} \mathrm{C}$ for $2 \mathrm{~min}$. Following cycling, the reaction mixture was finally heated at $72{ }^{\circ} \mathrm{C}$ for $5 \mathrm{~min}$. Amplified DNA was purified using a PCR Spinclean Kit (Progen) and sequenced across the Eco72I site in both directions.

Northern blot analysis. Total RNA was isolated from $P$. gingivalis W50 as previously described (Slakeski et al., 1996). Northern blots were prepared as described by Sambrook $e t$ al. (1989) and the blotted membranes hybridized with the oligonucleotide probe anti-sense to the amino acid sequence RMIVIVA present in the N-terminal sequence of PrtR45 (Slakeski et al., 1996). Hybridization and washing conditions were identical to those described above.

Purification of high-molecular-mass complexes of Arg-specific and Lys-specific proteinases and adhesins (PrtR-PrtK complexes). The high-molecular-mass, cell-associated proteinase-adhesin complexes (PrtR-PrtK complexes) of $P$. gingivalis W50 were purified using a combination of anionexchange, gel-filtration and Arg-Sepharose affinity chromatography from a cell sonicate as described previously (Bhogal et al., 1997). The complexes were characterized using SDSPAGE, transblotting and sequence analysis and assayed for enzyme activity using Bz-L-Arg- $p$ NA and $z-L-L y s-p N A$ substrates (Bhogal et al., 1997).

Solid-phase peptide synthesis. Peptides were synthesized manually using standard Fmoc solid-phase peptide synthesis protocols. The peptides were assembled as the carboxyamide form using Fmoc/Pal/Peg/PS resin (PerSeptive Biosystems). Coupling was accomplished with $\mathrm{HBTU} / \mathrm{HOBt}$ activation using four equivalents of $\mathrm{Fmoc}$-amino acid and six equivalents of DIPEA. The Fmoc group was removed by $2 \%(\mathrm{v} / \mathrm{v}) \mathrm{DBU}$ in DMF containing $2 \%(\mathrm{v} / \mathrm{v})$ piperidine. Cleavage of peptides from the resin support was performed using TFA/phenol/ TIPS/EDT/water $(92: 2: 2: 2: 2$, by vol.) cleavage cocktail for $2.5 \mathrm{~h}$. After cleavage the resin was removed by filtration and the filtrate concentrated to approximately $1 \mathrm{ml}$ under a stream of nitrogen. After the peptide products were precipitated in cold ether, they were centrifuged and washed three times. The peptide precipitate was then dissolved in $10 \mathrm{ml}$ water containing $0 \cdot 1 \%(\mathrm{v} / \mathrm{v})$ TFA and insoluble residue was removed by centrifugation.

Synthesized peptides were purified using a Brownlee C18 Aquapore ODS column $(250 \times 100 \mathrm{~mm})$ installed in a Waters HPLC system. Chromatograms were developed at a flow rate of $5.0 \mathrm{ml} \mathrm{min}^{-1}$ using $0.1 \%(\mathrm{v} / \mathrm{v})$ TFA in water (solvent A) and $0.1 \%(\mathrm{v} / \mathrm{v})$ TFA in $90 \%$ aqueous acetonitrile (solvent $\mathrm{B}$ ). Peptides were eluted with a gradient of $10-30 \%$ solvent $B$ over $40 \mathrm{~min}$. Analytical HPLC was carried out using a Brownlee C8 Aquapore RP-300 column $(220 \times 4.6 \mathrm{~mm})$ installed in an Applied Biosytems HPLC system. Chromatograms were developed using solvent $\mathrm{A}$ and solvent $\mathrm{B}$ at a flow rate of $1.0 \mathrm{ml} \mathrm{min}^{-1}$ and a $0-100 \%$ linear gradient of solvent B over $30 \mathrm{~min}$. Material eluted from the columns was monitored at $A_{214}$. Peptides were analysed by mass spectrometry using a PerSeptive Biosystems Voyager DE MALDI-TOF.

Competitive binding assay. Wells of flat-bottomed polyvinyl microtitre plates (Microtitre, Dynatech) were coated overnight at $4{ }^{\circ} \mathrm{C}$ using a solution $\left(5 \mu \mathrm{g} \mathrm{ml}^{-1}\right)$ of the adhesinbinding motif (ABM) peptide in $0.1 \mathrm{M}$ phosphate-buffered saline, $\mathrm{pH} 7 \cdot 4$, containing $0 \cdot 1 \%(\mathrm{v} / \mathrm{v})$ Tween $20($ PBST) and $0.1 \%(\mathrm{w} / \mathrm{v})$ sodium azide. After removal of the coating solution, $2 \%(\mathrm{w} / \mathrm{v})$ skim milk powder in PBST was added to block the remaining uncoated plastic for $1 \mathrm{~h}$ at room temperature and then washed $(4 \times$ PBST $)$. A solution $\left(1 \mu \mathrm{g} \mathrm{ml}^{-1}\right)$ of the PrtR-PrtK proteinase-adhesion complex (inactivated with $1 \mathrm{mM}$ TLCK) was incubated with known concentrations of $\mathrm{ABM}$ peptide, control peptide and casein for $1 \mathrm{~h}$ and then transferred to the microtitre plates coated with the ABM peptide. Following incubation for $2 \mathrm{~h}$ at $37{ }^{\circ} \mathrm{C}$ the plates were washed (5 $\times$ PBST). A 1:10000 dilution of rabbit anti-PrtR-PrtK antiserum in PBST containing $1 \%(\mathrm{w} / \mathrm{v})$ skim milk powder was then added to the washed wells and incubated for $2 \mathrm{~h}$ at $37^{\circ} \mathrm{C}$. Bound antibody was detected by incubation with horseradish-peroxidase-conjugated goat immunoglobulin (Ig) directed against rabbit Ig (Bio-Rad) for $1.5 \mathrm{~h}$ at $37^{\circ} \mathrm{C}$. After washing $(5 \times \mathrm{PBST})$, substrate $(0.4 \mathrm{mM}$ $3,3^{\prime}, 5,5^{\prime}$-tetramethylbenzidine in $0 \cdot 1 \mathrm{M}$ sodium acetate/citric acid buffer containing $0.004 \%, \mathrm{v} / \mathrm{v}$, hydrogen peroxide) was added and colour development was stopped by addition of $2 \mathrm{M} \mathrm{H}_{2} \mathrm{SO}_{4}$. $A_{450}$ was measured using a Bio-Rad microplate reader model 450 . 


\section{RESULTS}

\section{PrtRII50 Arg-specific proteinase purification and characterization}

The $P$. gingivalis W50 cell sonicate contained $0.36 \mathrm{mg}$ protein $\mathrm{ml}^{-1}$ and had activities of $2 \cdot 4$ and $1 \cdot 1 \mu \mathrm{mol} \mathrm{min}^{-1}$ (mg protein $)^{-1}$ with $1.0 \mathrm{mM} \mathrm{Bz-L-Arg-pNA}$ and z-L-Lys$p \mathrm{NA}$ as substrates, respectively, at $25^{\circ} \mathrm{C}$. The sonicate was subjected to Q-Sepharose anion-exchange FPLC, and proteolytic/amidolytic activity eluting between $160-246 \mathrm{mM} \mathrm{NaCl}$ was collected and concentrated using a Centripep and Centricon-10 concentrator (Amicon). This fraction represented the leading edge of the main peak of proteolytic/amidolytic activity and contained the highest ratio of Arg-specific activity to Lys-specific activity. After concentration, the fraction

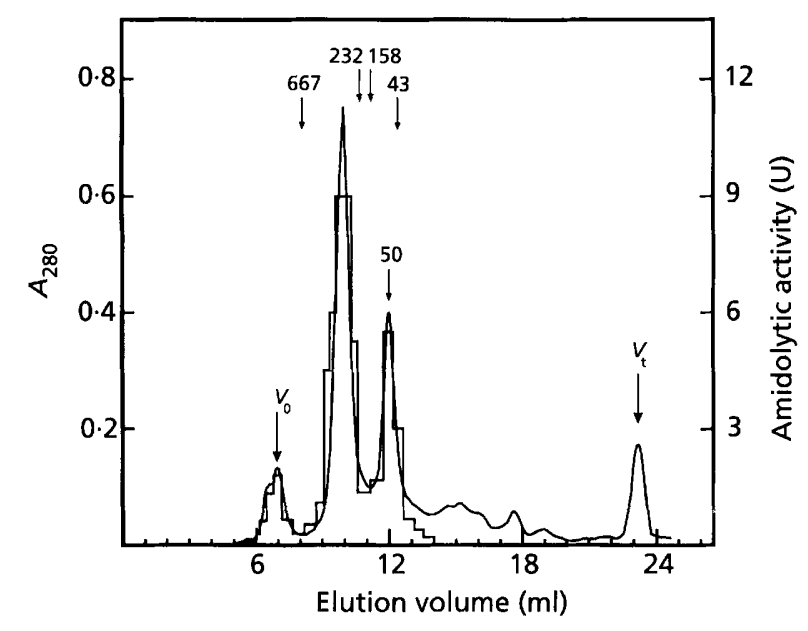

Fig. 1. Gel-filtration FPLC of pooled and concentrated fractions eluting from Q-Sepharose anion-exchange FPLC. Anionexchange fractions eluting between 160 and $246 \mathrm{mM} \mathrm{NaCl}$ and representing the leading edge of the main peak of proteolytic/amidolytic activity were pooled, equilibrated in TC buffer, $\mathrm{pH} 7 \cdot 4$, containing $50 \mathrm{mM} \mathrm{NaCl}$, concentrated and applied to a Superose 12 HR $10 / 30$ gel-filtration column using the same buffer at a flow rate of $0.3 \mathrm{ml} \mathrm{min}^{-1}$. Fractions $(0.5 \mathrm{ml})$ were assayed for proteolytic/amidolytic activity using azocasein, Bz-L-Arg-pNA and z-L-Lys-pNA. Amidolytic activity of each $0.5 \mathrm{ml}$ fraction with Bz-L-Arg-pNA is shown by the histogram.

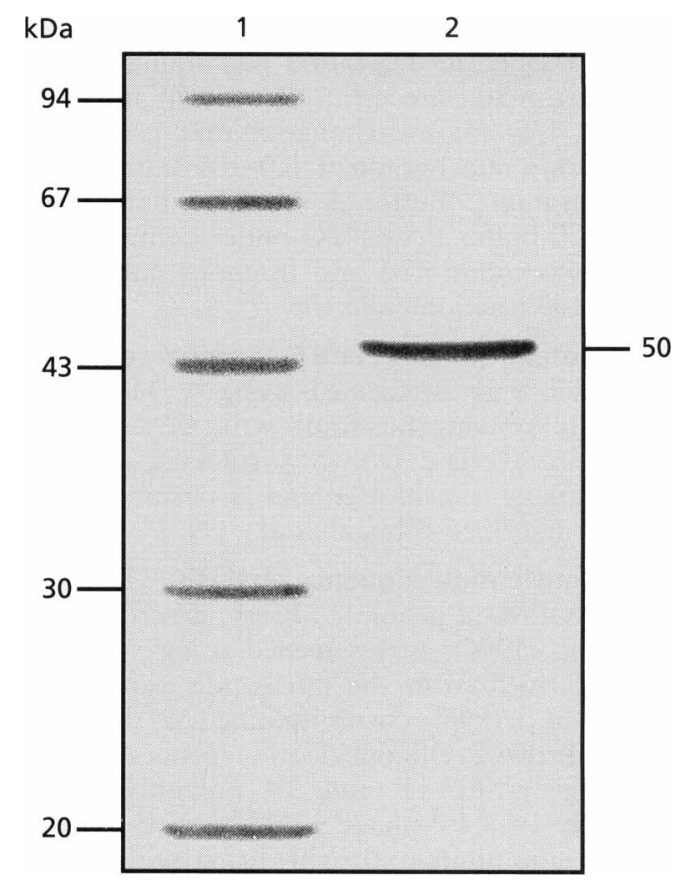

Fig. 2. SDS-PAGE (boiled/reduced conditions) of the anionexchange (Mono Q) peak eluting at $200 \mathrm{mM} \mathrm{NaCl}$ and containing only Arg-specific activity. Lane 1, Pharmacia lowmolecular-mass standards (molecular masses, in $\mathrm{kDa}$, are indicated); lane 2, purified $50 \mathrm{kDa}$ Arg-specific proteinase, PrtRII50.

was applied to a Superose 12 gel-filtration column (Fig. 1). Arg-and Lys-specific activity was associated with the high-molecular-mass eluting material corresponding to peaks with molecular masses of $0 \cdot 6-2 \cdot 0 \times 10^{6} \mathrm{Da}$ and $300 \mathrm{kDa}$, as reported previously (Bhogal et al., 1997). However, a lower-molecular-mass peak of $50 \mathrm{kDa}$ was also observed, which displayed only Arg-specific activity and this peak was collected for further purification. The $50 \mathrm{kDa}$ gel-filtration peak was applied to a Mono Q anion-exchange column and upon application of a $\mathrm{NaCl}$ gradient the Arg-specific activity eluted in a distinct peak at $200 \mathrm{mM} \mathrm{NaCl}$ with a 28 -fold purification over the original crude sonicate (Table 1). The peak containing Arg-specific activity was subjected to SDS-

Table 1. Purification of the $50 \mathrm{kDa}$ Arg-specific proteinase PrtRII50

\begin{tabular}{|lccccc|}
\hline Purification step & $\begin{array}{c}\text { Protein } \\
(\mathbf{m g})\end{array}$ & $\begin{array}{c}\text { Proteolytic } \\
\text { activity }\left(\mathbf{U}^{*}\right)\end{array}$ & $\begin{array}{c}\text { Specific activity } \\
\left(\mathbf{U ~ m g}^{-\mathbf{1}}\right)\end{array}$ & $\begin{array}{c}\text { Purification } \\
(- \text {-fold })\end{array}$ & Yield (\%) \\
\hline $\begin{array}{l}\text { Sonicate } \\
\begin{array}{l}\text { FPLC (Q-Sepharose) } \\
\text { anion-exchange }\end{array}\end{array}$ & $54 \cdot 0$ & 128 & $2 \cdot 4$ & 1 & 100 \\
$\begin{array}{l}\text { Gel-filtration } \\
\text { (Superose 12) FPLC }\end{array}$ & $0 \cdot 80$ & 10 & $10 \cdot 4$ & $4 \cdot 3$ & 22 \\
$\begin{array}{l}\text { FPLC (mono Q) } \\
\text { anion-exchange }\end{array}$ & $0 \cdot 12$ & 8 & $66 \cdot 7$ & $5 \cdot 2$ & 8 \\
\hline
\end{tabular}

*Amidolytic activity using $1.0 \mathrm{mM} \mathrm{Bz}-\mathrm{L}-\mathrm{Arg}-\mathrm{pNA} ; 1$ unit $=\mu \mathrm{mol} \mathrm{min} \mathrm{m}^{-1}$ at $25^{\circ} \mathrm{C}$. 


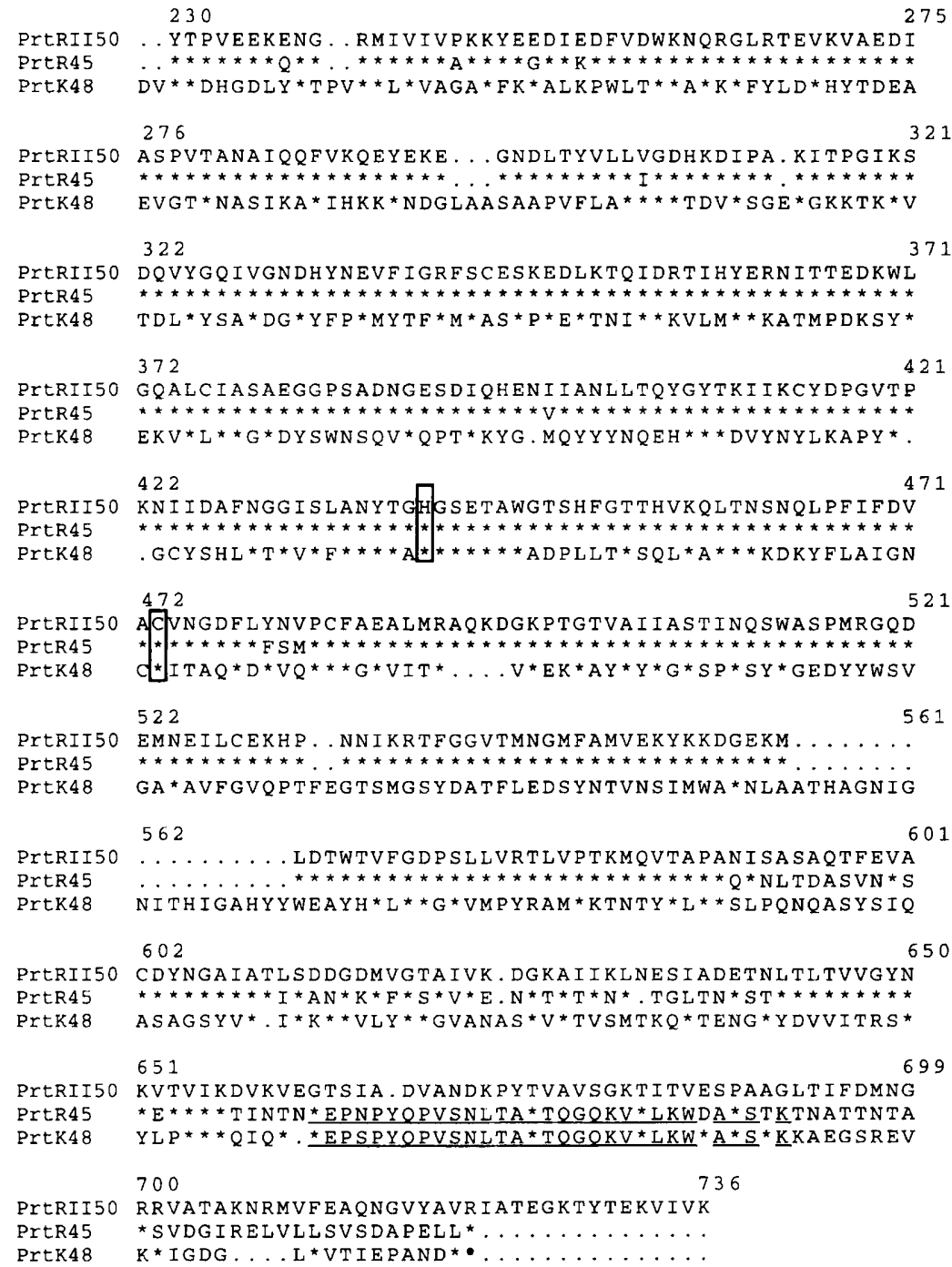

Fig. 3. Alignment of the deduced amino acid sequences of PrtRII50, PrtR45 Argspecific proteinase and PrtK48 Lys-specific proteinase with optimized similarity. The amino acyl residues of PrtRII50 are numbered from the Met initiation codon. An asterisk indicates an identical residue to that in PrtRII50. The underlined residues indicate the putative $A B M$. The putative catalytic $H$ is and $C y s$ residues are boxed.
PAGE, which confirmed a single $50 \mathrm{kDa}$ protein band (Fig. 2). The $50 \mathrm{kDa}$ band was transblotted and subjected to $\mathrm{N}$-terminal sequence analysis, which provided the amino acyl sequence YTPVEEKENGRMIVIVPKKYEEDIED. The specificity of the $50 \mathrm{kDa}$ proteinase for arginyl residues was confirmed by the enzyme cleaving Bz-L-Arg- $p$ NA but not z-L-Lys- $p$ NA. The Arg-specific $50 \mathrm{kDa}$ enzyme was activated by thiols (particularly cysteine), not inhibited by the serine proteinase inhibitors PMSF or 4-(2-aminoethyl)-benzenesulfonyl fluoride but inhibited by thiol-directed reagents, leupeptin and EDTA at similar concentrations to those which inhibited the PrtR45 (Bhogal et al., 1997). Inhibition with EDTA could be reversed by the addition of excess $\mathrm{Ca}^{2+}$ and the $\mathrm{pH}$ optimum of the enzyme was 8.0 with minimal activity below $\mathrm{pH} 6.0$.

\section{Molecular cloning and sequence analysis of the prtRII gene}

Screening of the $P$. gingivalis genomic library using oligonucleotide probes specific for the $\mathrm{N}$-terminus of PrtR45 identified several positive clones. The DNA from these clones was extracted and subjected to Southern analysis to identify those containing the $12 \mathrm{~kb} \mathrm{BamHI}$ fragment previously proposed to correspond to the gene encoding the second Arg-specific proteinase (Slakeski et al., 1996). Lambda clone 18, containing a $12 \mathrm{~kb} \mathrm{BamHI}$ fragment, was chosen for further analysis and DNA was isolated from this clone and digested with Eco72I and randomly cloned into plasmid SmaI-BAP pUC18. Adjacent 3.3 and $1.2 \mathrm{~kb}$ Eco72I genomic fragments were sequenced in both directions to generate the entire prtRII nucleotide sequence (GenBank accession no. AF007124). A 991 bp PCR fragment was generated and sequenced to confirm the sequence encompassing the internal Eco72I site.

The prtRII ORF comprises 2208 bp (736 aa residues) and encodes a preproprotein consisting of a putative leader sequence and a profragment followed by the mature Arg-specific proteinase (507 aa residues) containing the exact $\mathrm{N}$-terminal amino acyl sequence obtained for the purified $50 \mathrm{kDa}$ enzyme (PrtRII50). The $\mathrm{N}$-terminal sequence of the mature protein, like PrtR45, is immediately preceded by an Arg residue in the profragment. 

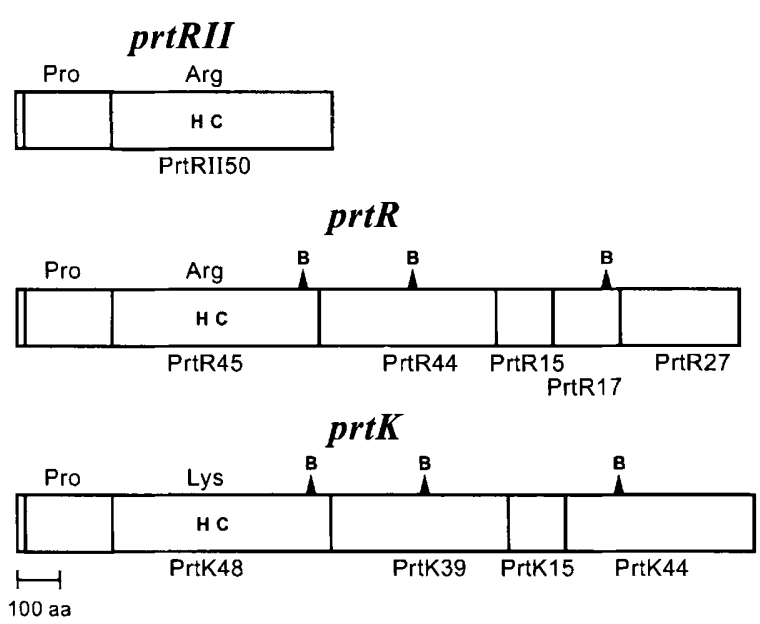

Fig. 4. Schematic representation of the prtRII, prtR and prtK genes. The PrtR nascent polyprotein consists of a leader sequence and a profragment followed by the PrtR45 Argspecific proteinase and the PrtR44, PrtR15, PrtR17 and PrtR27 adhesin domains. The PrtK nascent polyprotein similarly consists of a leader sequence, a profragment, the PrtK48 Lys-specific proteinase and the PrtK39, PrtK15 and PrtK44 adhesin domains. The PrtRII nascent polyprotein contains no associated adhesins and consists of a leader sequence, a profragment and the PrtRII50 Arg-specific proteinase only. B indicates the relative positions of the putative $A B M s$. $H$ and $C$ represent the location of the putative catalytic His, Cys dyad of the proteinases.

The prtRII gene exhibits a high degree of similarity with the $5^{\prime}$ two-fifths of the $p r t R$ gene which encodes PrtR45 and its associated adhesins (Figs 3 and 4). A comparison of the two translated sequences shows an overall similarity of $76 \%$ and $80 \%$ for the translated preprofragment and the proteinase domain, respectively. The prtRII gene, however, does not encode any of the Cterminal haemagglutinin/adhesin domains encoded by the $p r t R$ and $p r t K$ genes (Slakeski et al., 1996; N. Slakeski and others, unpublished data), this being consistent with the finding that the purified PrtRII50 proteinase was not associated with adhesins. The molecular mass of the PrtRII50 mature proteinase deduced from the translated $p r t R I I$ gene sequence is $55.6 \mathrm{kDa}$, which is consistent with the $50 \mathrm{kDa}$ obtained by SDS-PAGE (Fig. 2) and is slightly larger than the deduced molecular mass of $53.9 \mathrm{kDa}$ for PrtR 45 (Bhogal et al., 1997).

The sequence alignment of the deduced amino acyl sequence of PrtRII50 with the PrtR45 Arg-specific proteinase and the PrtK48 Lys-specific proteinase (Slakeski et al., 1996; Bhogal et al., 1997) shows that PrtRII50 displays high sequence similarity $(97.5 \%$ identity) to the adhesin-associated PrtR45 proteinase except for the C-terminal 80 amino acyl residues (Fig. 3). In fact, this C-terminal 80 residue sequence of PrtRII50 is similar ( $47 \%$ identity) to the C-terminal 80 residues of the PrtR27 adhesin domain, the last domain of PrtR (Fig. 4). In contrast to the high sequence identity of the PrtRII50 and PrtR45 proteinases, there is lower overall similarity $(25 \%$ identity) between the two adhesin-

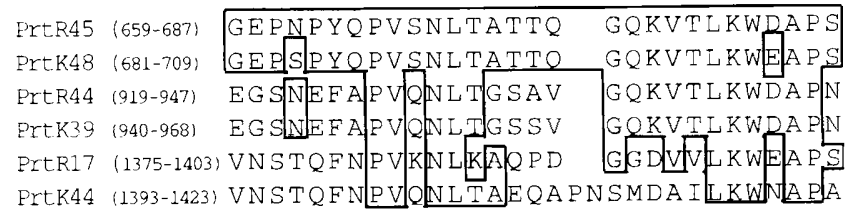

Fig. 5. Alignment of the putative $A B M s$ found in the PrtR45 Arg-specific proteinase, the PrtK48 Lys-specific proteinase, the PrtR44 and PrtR17 adhesins, and the PrtK39 and PrtK44 adhesins. Residues identical with PrtR45 (aa 659-687) are boxed and the amino acyl residues, shown in parentheses, are numbered from the Met initiation codon of all three gene products.

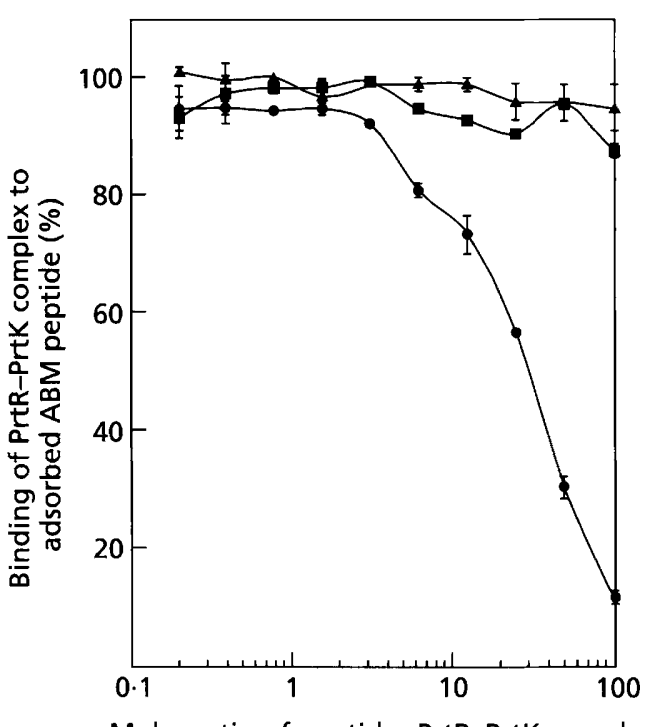

Fig. 6. Competitive binding assay demonstrating binding of the TLCK-inactivated PrtR-PrtK proteinase-adhesin complex to the synthetic peptide corresponding to the putative $A B M$. , ABM synthetic peptide PYQPVSNLTATTQGQKVTLKWDAPSTK; $\mathbf{\square}$, control peptide FNGGISLANYTGHGSETAWGT, corresponding to residues 199-219 of PrtR45; $\mathbf{\Delta}$, casein. See Methods for details.

associated PrtR45 and PrtK48 proteinases except around the C-terminal region where the motif GEPNPYQPVSNLTATTQGQKVTLKWDAPSTK (underlined in Fig. 3 ) is almost identical in both proteinases but is absent in PrtRII50. Similar motifs also occur in the PrtR44, PrtR17, PrtK39 and PrtK44 adhesin domains of PrtR and PrtK (Figs 4 and 5); this finding has led us to propose that this motif is an ABM involved in the association of the PrtR and PrtK proteinases and adhesins into large complexes.

\section{Binding of the PrtR-PrtK complex to a synthethic peptide corresponding to a putative $A B M$}

A peptide (ABM peptide) corresponding to the proposed ABM PYQPVSNLTATTQGQKVTLKWDAPSTK was synthesized and used to measure binding of the PrtR-PrtK complex. Specific binding of TLCK-in- 


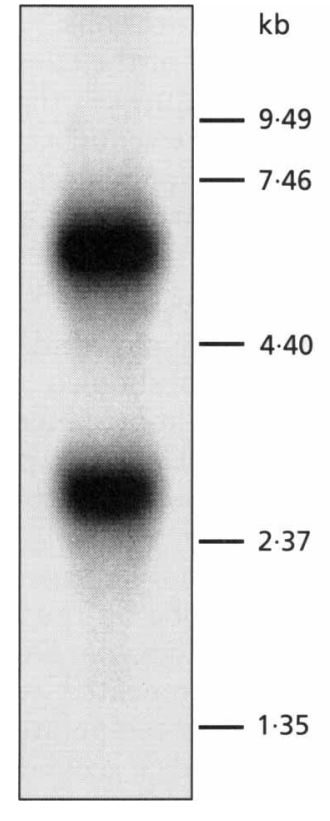

Fig. 7. Northern analysis of $P$. gingivalis RNA hybridized with an oligonucleotide specific for the PrtR45 N-terminal region which shows two positively hybridizing transcripts of 2.6 and $5.8 \mathrm{~kb}$. The relative positions of the RNA molecular size markers (kb) are indicated.

activated PrtR-PrtK complex to the ABM peptide was demonstrated in a competitive binding assay, where a 5-100-fold molar excess of the ABM peptide in solution was required to inhibit binding of the complex to the $\mathrm{ABM}$ peptide adsorbed onto the microtitre plate (Fig. 6). A control peptide, FNGGISLANYTGHGSETAWGT, corresponding to residues $428-448$ of PrtR45, as well as casein did not inhibit the binding of the TLCKinactivated PrtR-PrtK complex to the adsorbed ABM peptide. The anti-PrtR-PrtK antiserum did not bind to the ABM peptide in the absence of the PrtR-PrtK complex. The inactivation with TLCK ensured that the complex was not binding to the peptide through the active sites of the proteinases. This was also confirmed by lack of binding of the PrtR-PrtK complex to casein and a non-specific peptide of similar size and lysine content to the ABM peptide but of unrelated sequence. These results demonstrating specific binding of the TLCK-inactivated PrtR-PrtK complex to the ABM peptide therefore are consistent with the proposed role of this conserved motif in the association of the PrtR and PrtK proteinases and adhesins into large complexes.

\section{Northern analysis}

Northern analysis using the oligonucleotide probe antisense to an N-terminal amino acyl sequence of the proteinases of $p r t R$ and $p r t R I I$ revealed two positively hybridizing transcripts of $5 \cdot 8 \mathrm{~kb}$ and $2 \cdot 6 \mathrm{~kb}$ (Fig. 7).

\section{DISCUSSION}

Using a $P$. gingivalis W50 cell sonicate we have purified and characterized a second cell-associated, Arg-specific, calcium-stabilized cysteine proteinase that is almost identical to the previously characterized Arg-specific cysteine proteinase PrtR45 (Bhogal et al., 1997). However, despite the almost identical enzymic characteristics and inhibitor/activator profile to PrtR45, the second enzyme exhibits a number of key differences. Firstly, the second enzyme, designated PrtRII50, is a discrete enzyme not associated with adhesins. The Arg-specific cysteine proteinase, $\operatorname{PrtR} 45$, is a $45 \mathrm{kDa}$ component of a large multi-protein complex of Arg- and Lys-specific proteinases and adhesins (Bhogal et al., 1997). Secondly, PrtRII50 is slightly larger than PrtR45 on SDS-PAGE (molecular mass $50 \mathrm{kDa}$ ) and thirdly there are four amino acid substitutions in the first $25 \mathrm{~N}$-terminal residues of PrtRII50. PrtRII50 has a Glu at position 8 instead of Gln, a Pro at position 17 instead of Ala, a Glu at position 22 instead of Gly and a Glu at position 25 instead of the Lys in PrtR45 (Fig. 3). These differences in size and the $\mathrm{N}$-terminal amino acyl sequence were confirmed with the cloning and sequence analysis of the gene prtRII encoding the second Arg-specific proteinase.

The deduced amino acid sequence of the prtRII gene exhibits $98 \%$ identity with that of the recently reported rgpB gene from $P$. gingivalis ATCC 33277 (Nakayama, 1997), suggesting that these two genes represent the same locus in two different strains. However, the sequence for the mature proteinase of the $\operatorname{rg} p B$ gene does not contain three of the N-terminal amino acyl substitutions found in the prtRII gene product and only has the Gln $\rightarrow$ Glu substitution at position 8 . The substitutions at positions 17, 22 and 25 found in PrtRII50, that enabled the gene product to be unequivocally differentiated by $\mathrm{N}$-terminal sequence analysis from the mature PrtR45 proteinase of $\operatorname{prtR}(\operatorname{rgp} A)$, were not found in $r g p B$. In the current study the differences in $\mathrm{N}$-terminal sequence and size of the mature proteinases enabled the differentiation of the discrete $50 \mathrm{kDa} A r g$ specific proteinase (PrtRII50) from the $45 \mathrm{kDa}$ Argspecific proteinase (PrtR45) found associated with adhesins. The assignment of the two proteinases (PrtR45 and PrtRII50) to the two genes (prtR and prtRII respectively) has enabled identification of a conserved motif in the two adhesin-associated proteinases (PrtR45 and PrtK48) not found in the discrete PrtRII50. As the conserved motif was also found in several adhesins of $p r t R$ and $p r t K$ we propose that it is an $A B M$ involved in association of the $p r t R$ and $p r t K$ proteinases and adhesins into large complexes. This proposition is supported by the demonstration that a synthetic peptide corresponding to the conserved motif specifically binds to the TLCK-inactivated PrtR-PrtK complex.

Recently, Rangarajan et al. (1997) purified and characterized a second Arg-specific cysteine proteinase from the culture supernatant of a $P$. gingivalis W50 isogenic mutant lacking a functional prpRI (equivalent to $p r t R$ ). 
This second Arg-specific proteinase was of similar size (50-55 kDa), exhibited the same $\mathrm{N}$-terminal sequence and enzyme characteristics as PrtRII50 and was identified as a discrete enzyme not associated with adhesins. The results of Rangarajan et al. (1997) therefore are consistent with the results presented here that the cellassociated form of the second Arg-specific enzyme PrtRII50 is a discrete enzyme and not adhesin-associated.

The high sequence similarity (97.5\%) between PrtRII50 and the adhesin-associated PrtR45 suggests that prtR has arisen by gene duplication and recombination of ancestral prtRII and adhesin genes or, alternatively, that prtRII arose by gene duplication and deletion of the adhesin domains from an ancestral prt $R$ as previously suggested by Nakayama (1997) for the $r g p A$ and $\operatorname{rg} p B$ genes of $P$. gingivalis ATCC 33277 .

On further examination of the alignment of the deduced amino acyl sequence of PrtRII50 with the catalytic domains of the PrtR45 Arg-specific proteinase and the PrtK48 Lys-specific proteinase (Slakeski et al., 1996; Bhogal et al., 1997; N. Slakeski and others, unpublished data) some further interesting areas of similarity were revealed (Fig. 3). Although these three cysteine proteinases from $P$. gingivalis have no similarity with any of the other known families of cysteine proteinases, it is possible to speculate on the identity of the catalytic residues since only one His residue and two Cys residues are conserved in the three sequence-related enzymes. The catalytic Cys, His dyad of these enzymes therefore is likely to consist of $\mathrm{H}^{440}$ of PrtRII50, the only conserved His in the three proteinases. The identification of $\mathrm{H}^{440}$ as a catalytic residue is also suggested by the sequence $\mathrm{T} \mathrm{X}$ $\mathrm{H}^{440} \mathrm{G}$ XX TA of the three proteinases, conforming to part of the Prosite consensus signature sequence for the catalytic His of cysteine proteinases (Appel et al., 1994). The catalytic Cys is also likely to be one of the two conserved cysteinyl residues $\mathrm{C}^{473}$ and $\mathrm{C}^{484}$ in the three sequence-related proteinases, although neither have flanking sequences that conform to the Prosite consensus signature sequence for the catalytic Cys of cysteine proteinases (Appel et al., 1994). Using active-site labelling of a $44 \mathrm{kDa}$ Arg-specific proteinase of $P$. gingivalis with $N-\left[\alpha-{ }^{3} \mathrm{H}\right]$ acetyllysine chloromethyl ketone, Nishikata \& Yoshimura (1995) identified a labelled peptide in an endoproteinase Asp- $\mathrm{N}$ digest with an $\mathrm{N}$-terminal sequence Asp-Val-Ala-Cys". This cysteine corresponds to $\mathrm{C}^{473}$ of PrtRII50 (Fig. 3), which is consistent with this residue being involved in catalysis.

In the cysteine proteinase papain, the catalytic mechanism has been proposed to involve, as well as the catalytic $\mathrm{Cys}^{25}$, $\mathrm{His}^{159}$ thiolate/imidazolium ion pair, stabilization of the oxyanion transition state by the $\mathrm{NH}_{2}$ group of the Gln ${ }^{19}$ side chain and stabilization of the thiolate/imidazolium ion pair by the side chain of $\mathrm{Asn}^{175}$ (Otto \& Schirmeister, 1997). In the alignment of the amino acyl sequences of the three sequence-related cysteine proteinases from $P$. gingivalis, one $G \ln \left(Q^{33}\right)$ and seven Asn $\left(\mathrm{N}^{238}, \mathrm{~N}^{429}, \mathrm{~N}^{436}, \mathrm{~N}^{461}, \mathrm{~N}^{510}, \mathrm{~N}^{524}\right.$ and
$\mathrm{N}^{650}$ ) residues of PrtRII50 are conserved in both PrtR45 and PrtK48 (Fig. 3). None of the conserved asparaginyl residues have flanking sequences that conform to the Prosite consensus signature sequence for the active site $\mathrm{N}$ of cysteine proteinases (Appel et al., 1994), so it is difficult to predict which Asn, if any, may be involved in catalysis.

Previous Northern analysis of $P$. gingivalis RNA hybridized with an oligonucleotide specific for the PrtR45 N-terminal region showed a single positively hybridizing transcript of approximately $5.3 \mathrm{~kb}$ which corresponded to the transcript of the prtR gene (Slakeski et al., 1996). In the present study, the N-terminal sequence analysis of the purified PrtRII50 revealed differences to the N-terminal sequence of PrtR45, which was used to design the probe for the Northern analysis. Considering these differences, the Northern analysis of $P$. gingivalis RNA was repeated with less stringent hybridization and washing temperatures. The repeated Northern analysis showed a second positively hybridizing transcript in the RNA preparations analysed (Fig. 7). In addition to the $5.8 \mathrm{~kb}$ transcript (previously estimated as $5 \cdot 3 \mathrm{~kb}$ ) corresponding to $p r t R$, the presence of a second transcript of approximately $2.6 \mathrm{~kb}$ is appropriately sized to indicate transcriptional activity of prtRII.

The absence of the proposed ABM on PrtRII50 would explain why this enzyme is not found associated with adhesins like PrtR45 and PrtK48 in the large proteinase-adhesin complexes (Bhogal et al., 1997). The adhesins, by containing multiple repeat sequences (Slakeski et al., 1996), would possess multiple binding sites capable of binding to host proteins and to this Cterminal motif on the PrtR 45 and PrtK48 proteinases as well as to themselves. The presence of the ABM would explain why after autolytic processing of the PrtR and PrtK polyproteins, the domains, consisting of the two proteinases PrtR45 and PrtK48 and the seven sequencerelated adhesins (Fig. 4), remain associated in large, non-covalently associated aggregates (Bhogal et al., 1997). The association of the adhesins with the proteinases is likely to be a mechanism by which the proteolytic activity is targeted to the desired substrates and the non-covalent nature of the association allows release of the proteinase once localized (Bhogal et al., 1997). It is also possible that the association of the cellassociated adhesins with the proteinases facilitates cell adhesion by the proteolytic activity exposing buried binding sites (cryptitopes) on host substrates (Kontani et al., 1996). Further, the multiple binding sites and autoaggregation of the adhesins would facilitate the formation of large complexes capable of cell-cell interaction and agglutination.

The lack of the putative ABM on the second Arg-specific proteinase, PrtRII50, could indicate that this enzyme's role is primarily as a periplasmic processing enzyme. Observations that would be consistent with this speculation are that the enzyme is found in a periplasmic extract of chloroform-treated cells ( $\mathrm{P}$. Bhogal and others, unpublished data) and several workers have 
implicated Arg-specific proteolytic activity in the processing of $P$. gingivalis extracellular proteins (Okamoto et al., 1996; Nakayama et al., 1996; Tokuda et al., 1996). However, as Rangarajan et al. (1997) have purified and characterized a second Arg-specific cysteine proteinase equivalent to PrtRII50 in the culture supernatant of a $P$. gingivalis isogenic mutant lacking a functional $p r p R I$ (equivalent to $p r t R$ ), then this result may suggest that PrtRII50 is both cell-associated and released into the culture fluid, as are the mature PrtR and PrtK such that this second Arg-specific proteinase may also play a direct role in the pathogenic potential of $P$. gingivalis.

We have previously reported that several groups have characterized structurally different genes encoding apparently the same Arg-specific proteinase from $P$. gingivalis with characteristics equivalent to PrtR45 (Slakeski et al., 1996). The genes characterized have been designated $p r t R$ (Slakeski et al., 1996), rgp (Pavloff et al., 1995), prpRI (Aduse-Opoku et al., 1995), agp (Okamoto et al., 1995) and cpgR (Gharbia \& Shah, 1995). Upon comparison it is apparent that the genes $p r t R, r g p$ and revised $p r p R I$ represent strain variations of the same genetic locus and the genes agp and $c p g R$ represent internally deleted and truncated versions, respectively, that may be a consequence of cloning and sequencing artefacts, or alternatively may represent a closely related gene at a second locus. In this paper we have characterized the sequence-related Arg-specific proteinase of the second genetic locus and the size and sequence of the gene are not consistent with agp or $\operatorname{cpg} R$.

\section{Concluding remarks}

In conclusion, we have identified a second Arg-specific, calcium-stabilized cysteine proteinase of $P$. gingivalis which is a discrete $50 \mathrm{kDa}$ protein with no adhesin association and which is encoded by the gene designated prtRII.

\section{ACKNOWLEDGEMENTS}

The expert technical assistance of Steven Cleal and Peter Riley is gratefully acknowledged. This research was supported by Australian National Health and Medical Research Council project grant 960231 .

\section{REFERENCES}

Aduse-Opoku, J., Muir, J., Slaney, J. M., Rangarajan, M. \& Curtis, M. A. (1995). Characterization, genetic analysis, and expression of a protease antigen (PrpRI) of Porphyromonas gingivalis W50. Infect Immun 63, 4744-4754.

Appel, R. D., Bairoch, A. \& Hochstrasser, D. F. (1994). A new generation of information retrieval tools for biologists: the example of the ExPASy WWW server. Trends Biochem Sci 19, 258-260.

Bhogal, P. S., Slakeski, N. \& Reynolds, E. C. (1997). Characterization of a cell-associated, protein complex of Porphyromonas gingivalis W50 containing Arg- and Lys-specific cysteine proteinases and adhesins. Microbiology 143, 2485-2495.

Chen, Z., Potempa, J., Polanowski, A., Wikstrom, M. \& Travis, J. (1992). Purification and characterization of a $50-\mathrm{kDa}$ cysteine proteinase (gingipain) from Porphyromonas gingivalis. $J$ Biol Chem 267, 18896-18901.

Ciborowski, P., Nishikata, M., Allen, R. D. \& Lantz, M. S. (1994). Purification and characterization of two forms of a highmolecular-weight cysteine proteinase (porphypain) from Porphyromonas gingivalis. J Bacteriol 176, 4549-4557.

Curtis, M. A., Aduse-Opoku, J., Slaney, J. M., Rangarajan, M., Booth, V., Cridland, J. \& Shepherd, P. (1996). Characterization of an adherence and antigenic determinant of the ArgI protease of Porphyromonas gingivalis which is present on multiple gene products. Infect Immun 64, 2532-2539.

Cutler, C. W., Kalmar, J. R. \& Genco, C. A. (1995). Pathogenic strategies of the oral anaerobe, Porphyromonas gingivalis. Trends Microbiol 3, 45-51.

Gharbia, S. E. \& Shah, H. N. (1995). Molecular analysis of surfaceassociated enzymes of Porphyromonas gingivalis. Clin Infect Dis 20, S160-S166.

Imamura, T., Potempa, J., Pike, R. N., Moore, J. N., Barton, M. H. \& Travis, J. (1995a). Effect of free and vesicle-bound cysteine proteinases of Porphyromonas gingivalis on plasma clot formation: implications for bleeding tendency at periodontitis sites. Infect Immun 63, 4877-4882.

Imamura, T., Potempa, J., Pike, R. N. \& Travis, J. (1995b). Dependence of vascular permeability enhancement on cysteine proteinases in vesicles of Porphyromonas gingivalis. Infect Immun 63, 1999-2003.

Jagels, M. A., Travis, J., Potempa, J., Pike, R. \& Hugli, T. E. (1996). Proteolytic inactivation of the leukocyte C5a receptor by proteinases derived from Porphyromonas gingivalis. Infect Immun 64, 1984-1991.

Kadowaki, T., Yoneda, M., Okamoto, K., Maeda, K. \& Yamamoto, K. (1994). Purification and characterization of a novel argininespecific cysteine proteinase (argingipain) involved in the pathogenesis of periodontal disease from the culture supernatant of Porphyromonas gingivalis. J Biol Chem 269, 21371-21378.

Kesavalu, L., Holt, S. C. \& Ebersole, J. L. (1996). Trypsin-like protease activity of Porphyromonas gingivalis as a potential virulence factor in a murine lesion model. Microb Pathog 20, $1-10$.

Kontani, M., Ono, H., Shibata, H., Okamura, Y., Tanaka, T., Fujiwara, T., Kimura, S. \& Hamada, S. (1996). Cysteine protease of Porphyromonas gingivalis 381 enhances binding of fimbriae to cultured human fibroblasts and matrix proteins. Infect Immun 64 , 756-762.

Laemmli, U. K. (1970). Cleavage of structural proteins during the assembly of the head of bacteriophage T4. Nature 227, 680-685.

Maiden, M. F. J., Carman, R. J., Curtis, M. A., Gillett, I. R., Griffiths, G. S., Sterne, J. A. C., Wilton, J. M. A. \& Johnson, N. W. (1990). Detection of high-risk groups and individuals for periodontal diseases: laboratory markers based on the microbiological analysis of subgingival plaque. J Clin Periodontol 17, 1-13.

Nakayama, K. (1997). Domain-specific rearrangement between the two Arg-gingipain-encoding genes in Porphyromonas gingivalis: possible involvement of nonreciprocal recombination. Microbiol Immunol 48, 185-196.

Nakayama, K., Kadowaki, T., Okamoto, K. \& Yamamoto, K. (1995). Construction and characterization of arginine-specific cysteine proteinase (Arg-gingipain)-deficient mutants of Porphyromonas gingivalis. Evidence for significant contribution of Arg-gingipain to virulence. J Biol Chem 270, 23619-23626.

Nakayama, K., Yoshimura, F., Kadowaki, T. \& Yamamoto, K. (1996). Involvement of arginine-specific cysteine proteinase (Arg- 
gingipain) in fimbriation of Porphyromonas gingivalis. J Bacteriol 178, 2818-2824.

Nishikata, M. \& Yoshimura, F. (1995). Active site structure of a haemagglutinating protease from Porphyromonas gingivalis: similarity to clostripain. Biochem Mol Biol Int 37, 547-553.

Okamoto, K., Misumi, Y., Kadowaki, T., Yoneda, M., Yamamoto, K. \& Ikehara, Y. (1995). Structural characterization of argingipain, a novel arginine-specific cysteine proteinase as a major periodontal pathogenic factor from Porphyromonas gingivalis. Arch Biochem Biophys 316, 917-925.

Okamoto, K., Kadowaki, T., Nakayama, K. \& Yamamoto, K. (1996). Cloning and sequencing of the gene encoding a novel lysine-specific cysteine protease (lys-gingipain) in Porphyromonas gingivalis: structural relationship with arginine-specific cysteine protease (arg-gingipain). J Biochem 120, 398-406.

Otto, H.-H. \& Schirmeister, T. (1997). Cysteine proteases and their inhibitors. Chem Rev 97, 133-171.

Pavloff, N., Potempa, J., Pike, R. N., Prochazka, V., Kiefer, M. C. Travis, J. \& Barr, P. J. (1995). Molecular cloning and structural characterization of the Arg-gingipain proteinase of Porphyromonas gingivalis. J Biol Chem 270, 1007-1010.

Pike, R. N., Potempa, J., McGraw, W., Coetzer, T. H. T. \& Travis, J. (1996). Characterization of the binding activities of proteinaseadhesin complexes from Porphyromonas gingivalis. J Bacteriol 178, 2876-2882.

Rangarajan, M., Aduse-Opoku, J., Slaney, J. M., Young, K. A. \& Curtis, M. A. (1997). The $p r p R 1$ and $p r R 2$ arginine-specific protease genes of Porphyromonas gingivalis W50 produce five biochemically distinct enzymes. Mol Microbiol 23, 955-965.

Sambrook, J., Fritsch, E. F. \& Maniatis, T. (1989). Molecular Cloning: a Laboratory Manual, 2nd edn. Cold Spring Harbor NY: Cold Spring Harbor Laboratory.

Slakeski, N., Cleal, S. M. \& Reynolds, E. C. (1996). Characterization of a Porphyromonas gingivalis gene prtR that encodes an arginine-specific thiol proteinase and multiple adhesins. Biochem Biophys Res Commun 224, 605-610.

Slots, J., Bragd, L., Wilkström, M. \& Dahlen, G. (1986). The occurrence of Actinobacillus actinomycetemcomitans, Bacteroides gingivalis and Bacteroides intermedius in destructive periodontal disease in adults. J Clin Periodontol 13, 570-577.

Smalley, J. W., Birss, A. J., Kay, H. M., McKee, A. S. \& Marsh, P. D. (1989). The distribution of trypsin-like enzyme activity in cultures of a virulent and an avirulent strain of Bacteroides gingivalis W50. Oral Microbiol Immunol 4, 178-181.

Socransky, S. S. \& Haffajee, A. D. (1992). The bacterial etiology of destructive periodontal disease: current concepts. J Periodontol 63, 322-331.

Tokuda, M., Duncan, M., Cho, M. I. \& Kuramitsu, H. K. (1996). Role of Porphyromonas gingivalis protease activity in colonization of oral surfaces. Infect Immun 64, 4067-4073.

Received 15 October 1997; revised 23 December 1997; accepted 2 March 1998. 